\title{
Vesicular Glutamate Transporter 1 (VGLUT1)- and VGLUT2-containing Terminals on the Rat Jaw-closing $\gamma$-Motoneurons
}

\author{
Sook Kyung Park ${ }^{1 \dagger}$, Jae Hyun Hong ${ }^{1 \dagger}$, Jae Kwang Jung ${ }^{2}$, \\ Hyoung-Gon $\mathrm{Ko}^{1}$ and Yong Chul Bae ${ }^{1 *}$ \\ Departments of ${ }^{1}$ Anatomy and Neurobiology, ${ }^{2}$ Oral Medicine, School of Dentistry, Kyungpook National University, \\ Daegu 41940, Korea
}

\begin{abstract}
Currently, compared to jaw-closing (JC) a-motoneurons, the information on the distribution and morphology of glutamatergic synapses on the jaw-closing (JC) $\gamma$-motoneurons, which may help elucidate the mechanism of isometric contraction of the JC muscle, is very limited. This study investigated the distribution and ultrastructural features of vesicular glutamate transporter 1 (VGLUT1)and VGLUT2-immunopositive (+) axon terminals (boutons) on JC $\gamma$-motoneurons by retrograde tracing with horseradish peroxidase, electron microscopic immunocytochemistry, and quantitative analysis. About $35 \%$ of the boutons on identified JC $\gamma$-motoneurons were VGLUT+, and of those, 99\% were VGLUT2+. The fraction of VGLUT1+ boutons of all boutons and the percentage of membrane of JC $\gamma$-motoneurons covered by these boutons were significantly lower than those for the JC $a$-motoneurons, revealed in our previous work. The bouton volume, mitochondrial volume, and active zone area of the VGLUT2+ boutons on the JC $\gamma$-motoneurons were uniformly small. These findings suggest that the JC $\gamma$-motoneurons, in contrast to the JC $a$-motoneurons, receive generally weak glutamatergic synaptic input almost exclusively from VGLUT2+ premotoneurons that form direct synapse with motoneurons.
\end{abstract}

Key words: Jaw closing $\gamma$-motoneuron, Glutamatergic synapse, Vesicular glutamate transporter, Immunohistochemistry, Electron microscopy

\section{INTRODUCTION}

Vesicular glutamate transporters (VGLUT) are involved in the uploading of cytoplasmic glutamate into synaptic vesicles and thus

Received April 6, 2019, Revised May 22, 2019,

Accepted July 8, 2019

* To whom correspondence should be addressed.

TEL: 82-53-660-6860, FAX: 82-53-426-7731

e-mail:ycbae@knu.ac.kr

${ }^{\dagger}$ S.K. Park and J.H. Hong contributed equally to this work. play an important role in the glutamatergic synaptic transmission $[1,2]$. VGLUT1 and VGLUT2, two major isoforms of VGLUT in the brain, are expressed in two functionally-distinct subpopulations of glutamatergic synapses that differ in their probability of transmitter release and capacity for synaptic plasticity and are routinely used as markers for these synapses [1,2].

The glutamatergic synapses on jaw-closing (JC) motoneurons in the brain stem mediate smooth and rhythmical movements of the jaw during mastication [3]. $\alpha$-Motoneurons and $\gamma$-motoneurons, which innervate extrafusal and intrafusal fibers in the JC muscle, respectively, differ in their morphological and electrophysiologi- 
cal properties, and in the distribution pattern of the inhibitory synapses they receive $[4,5]$. We recently reported distinct synaptic morphology and distribution patterns of VGLUT-immunopositive (+) boutons on the Jaw-closing (JC) and -opening (JO) $\alpha$-motoneurons: while JC $\alpha$-motoneurons receive synapses from numerous VGLUT1+ trigeminal mesencephalic neurons that innervate muscle spindles, JO $\alpha$-motoneurons rarely receive synapses from VGLUT1+ neurons [6]. However, little information is available about glutamatergic synapses on the JC $\gamma$-motoneurons that play a crucial role in isometric contraction of the JC muscle, i.e., contraction of JC muscle without change in its length and with increasing contraction strength, during chewing food.

To help understand better the mechanism of regulation of isometric contraction of JC muscles, we investigated the distribution and morphology of the VGLUT1+ and VGLUT2+ boutons on the JC $\gamma$-motoneurons by retrograde tracing with horseradish peroxidase, electron microscopic immunocytochemistry, and quantitative analysis.

\section{MATERIALS AND METHODS}

\section{Labeling of JC $\gamma$-motoneurons and tissue preparation}

All procedures involving experimental animals were following the guidelines of the National Institutes of Health and carried out with approval by the IACUC at the Kyungpook National University.

Four adult male Sprague-Dawley rats (300 350 g) were injected into multiple sites of the right masseteric muscle with a total $8 \mu \mathrm{l}$ of $30 \%$ isotonic solution of type IV horseradish peroxidase (HRP, TOYOBO, Japan) after intraperitoneal anesthesia with $40 \mathrm{mg} /$ $\mathrm{kg}$ sodium pentobarbital. Rats were re-anesthetized 48 72 hours after the surgery and perfused through the aorta with a solution of $0.01 \%$ glutaraldehyde and $4 \%$ paraformaldehyde in phosphate buffer ( $\mathrm{PB} ; 0.1 \mathrm{M}, \mathrm{pH}$ 7.4). Tissue blocks containing the brain stem were fixed in the fixative used for perfusion for additional 2 hours, and $60 \mu \mathrm{m}$-thick transverse Vibratome sections were collected in $\mathrm{PB}$ and stored at $4{ }^{\circ} \mathrm{C}$. The HRP was visualized with tungstate and tetramethylbenzidine $[7,8]$ and sections of the brain stem at the level of the trigeminal motor nucleus (Vmo) were cryoprotected in $30 \%$ sucrose in PB overnight at $4^{\circ} \mathrm{C}$.

\section{Electron microscopic immunostaining for VGLUT1 and VGLUT2}

Double immunostaining for VGLUT1 and VGLUT2 was performed as previously described $[6,9]$. Briefly, sections processed for freeze-thaw penetration enhancement were treated with $1 \%$ sodium borohydride, $3 \% \mathrm{H}_{2} \mathrm{O}_{2}$, and $10 \%$ normal donkey serum.
The primary antibodies (Guinea pig anti-VGLUT1, 1:2,000, Cat. No. 135 304, and rabbit anti-VGLUT2, 1:1,000, Cat. No. 135 402, Synaptic Systems, Göttingen, Germany) were applied overnight in a mixture at room temperature. The secondary antibodies (biotinylated donkey anti-guinea pig, 1:200, Jackson Immunoresearch, West Groove, PA, USA and donkey anti-rabbit IgG conjugated to 1 nm gold particles, 1:50, EMS, Hatfield, PA, USA) were also applied in a mixture for 2 hours. After rinsing, the sections were incubated with 2\% glutaraldehyde in PBS for 10 minutes, IntenSE ${ }^{\mathrm{TM}}$ silver intensification solution (Amersham, Arlington Heights, IL, USA) for 6 minutes, $0.1 \mathrm{M}$ sodium acetate and PB for 10 minutes, and ExtrAvidin peroxidase (1:5,000; Sigma-Aldrich, St. Louis, MO, USA) for 1 hour. The immunoperoxidase was then revealed with nickelintensified diaminobenzidine. Processing for electron microscopy was performed as previously described [10,11]. In brief, sections were osmicated ( $0.5 \%$ osmium tetroxide in $\mathrm{PB}, \mathrm{pH} 6.0)$, dehydrated in ethanol, embedded in Durcupan ACM (Fluka, Switzerland), and cured for 48 hours at $60^{\circ} \mathrm{C}$. Serial thin sections were cut on formvar-coated grids from areas of the wafers containing multiple HRP-labeled neurons, treated with uranyl acetate and lead citrate, and examined on a Hitachi H-7500 electron microscope at $80 \mathrm{kV}$. Digital electron micrographs were acquired with a CCD camera (SC1000; Gatan, Pleasanton, CA, USA), and saved as TIFF files.

Preadsorption with $15 \mu \mathrm{g} / \mathrm{ml}$ blocking peptides (VGLUT1 Cat. No. 135-30P, and VGLUT2, Cat. No. 135-40P, Synaptic Systems) or omission of primary or secondary antibodies completely abolished the specific staining.

\section{Identification of JC $\gamma$-motoneurons}

Spinal or trigeminal $\gamma$-motoneurons are smaller in size and a smaller percentage of their somatic membrane is covered by synaptic boutons than $\alpha$-motoneurons $[4,12]$. We elaborated that further by showing that the somata of identified JC motoneurons had a diameter of around $22 \mu \mathrm{m}$, corresponding to $\gamma$-motoneurons, or around $42 \mu \mathrm{m}$, corresponding to $\alpha$-motoneurons, and that the percent synaptic covering of $\gamma$-motoneurons is one fourth of that of a-motoneurons [4]. Based on these criteria, HRP-labeled JC motoneurons with $<22 \mu \mathrm{m}$ in diameter and $<20 \%$ in synaptic covering percentage were identified as $\gamma$-motoneurons and selected for analysis.

\section{Quantitative analysis}

The frequency of VGLUT+ boutons on somata and primary dendrites of identified JC $\gamma$-motoneurons and their synaptic coverage were analyzed in electron micrographs $(20,000 \times)$ of every other section through entire VGLUT2 boutons on JC $\gamma$-motoneurons completely or nearly completely reconstructed from serial sections. 
Bouton volume and mitochondrial volume were computed from cross-sectional areas, and active zone areas were computed from lengths of active zones measured with a digitizing tablet and Image
J software. Inter-animal variability in the values of VGLUT1+ and VGLUT2+ boutons on each JC $\gamma$-motoneuron was not significant (one-way ANOVA), and the data could be pooled for the analysis.
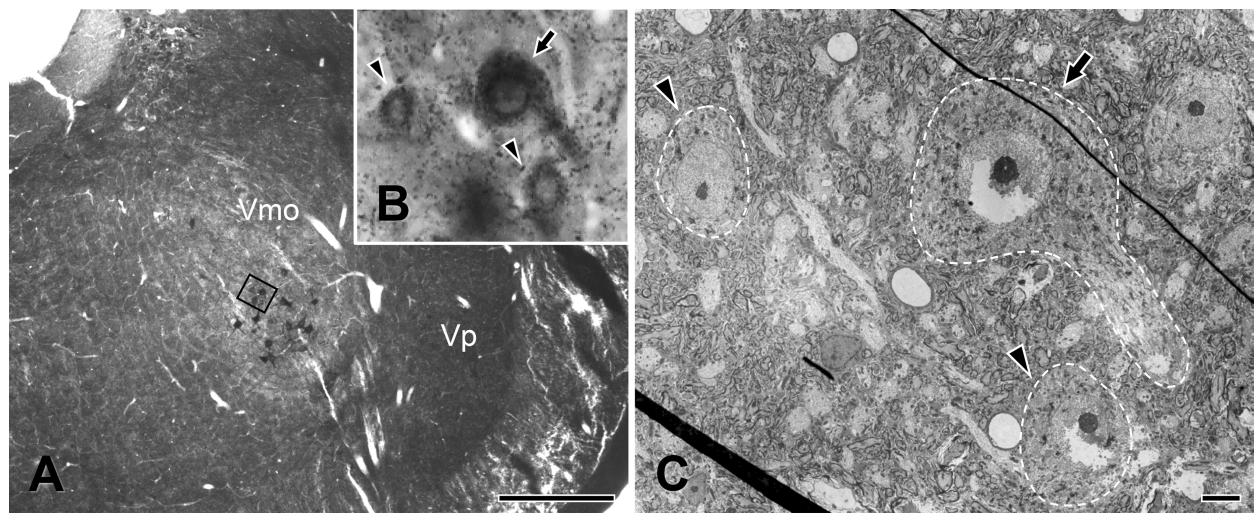

Fig. 1. Light (A, B) and electron micrographs (C) showing HRP-labeled, jaw-closing a-motoneuron (arrow) and $\gamma$-motoneurons (arrowheads) in the trigeminal motor nucleus (Vmo). B is an enlargement of the boxed area in A, and C is a further enlargement of the same field obtained with electron microscopy. Vp in A indicates the principal trigeminal nucleus. The boundaries of the motoneurons are outlined with a dashed line in C. Scale bars, $500 \mu \mathrm{m}$ in $\mathrm{A}$ and $5 \mu \mathrm{m}$ in $\mathrm{C}$.
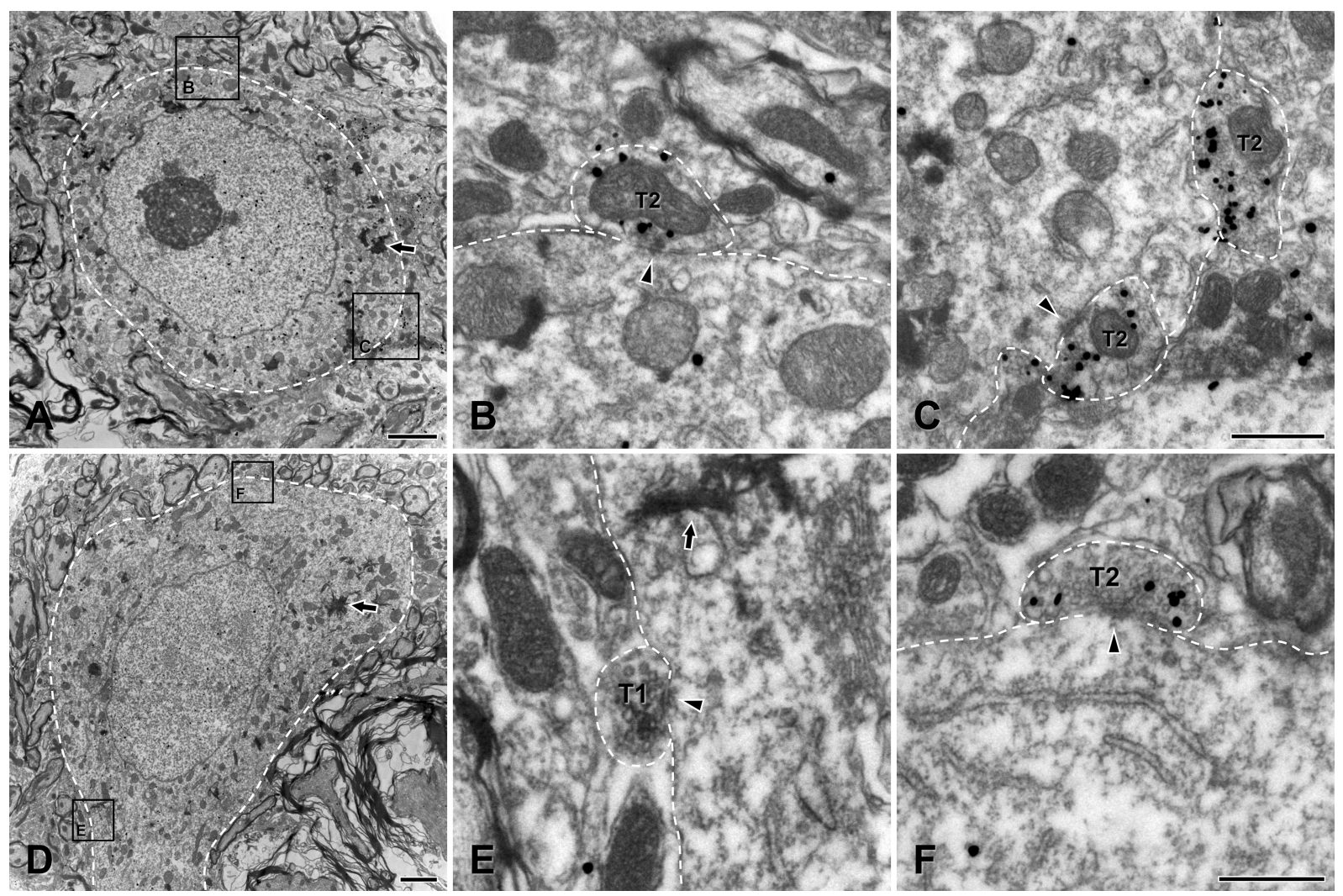

Fig. 2. Electron micrographs showing two (A C and D F) HRP-labeled, jaw-closing $\gamma$-motoneurons in the trigeminal motor nucleus (the reaction product of retrogradely-transported HRP is indicated by arrows), contacted by VGLUT1+ bouton (T1, peroxidase labeling) and VGLUT2+ boutons (T2, gold-silver labeling). B and C are enlargements of the boxed areas in A; E and F are enlargements of the boxed areas in D. The boundaries of the somata of the motoneurons and the VGLUT+ boutons in contact with them are outlined with a dashed line. Arrowheads indicate synapses. Scale bars, $2 \mu \mathrm{m}$ in A and $\mathrm{D}$, and $500 \mu \mathrm{m}$ in $\mathrm{B}, \mathrm{C}, \mathrm{E}$ and $\mathrm{F}$. 
Differences of VGLUT+ boutons on JC $\gamma$-motoneurons vs. on a-motoneurons (data from our previously-published experiments; [6]) were analyzed with ANOVA and Scheffe's F-test; significance was set at $\mathrm{p}<0.05$.

\section{RESULTS AND DISCUSSION}

With light microscopy, HRP-labeled JC motoneurons were observed in the dorsolateral part of the trigeminal motor nucleus (Vmo, Fig. 1). With electron microscopy, the labeled neurons were identified by the presence of crystalline or amorphous deposits of HRP reaction product in the cytoplasm. VGLUT1+ boutons apposing HRP-labeled motoneurons were identified by the presence of electron-dense immunoperoxidase reaction product in the axoplasm, and VGLUT2+ boutons were identified by the presence of multiple gold-silver particles in the axoplasm; both VGLUT1+ and VGLUT2+ boutons contained many round vesicles (Fig. 2 and 3).

The frequency and percent synaptic covering of the VGLUT1+
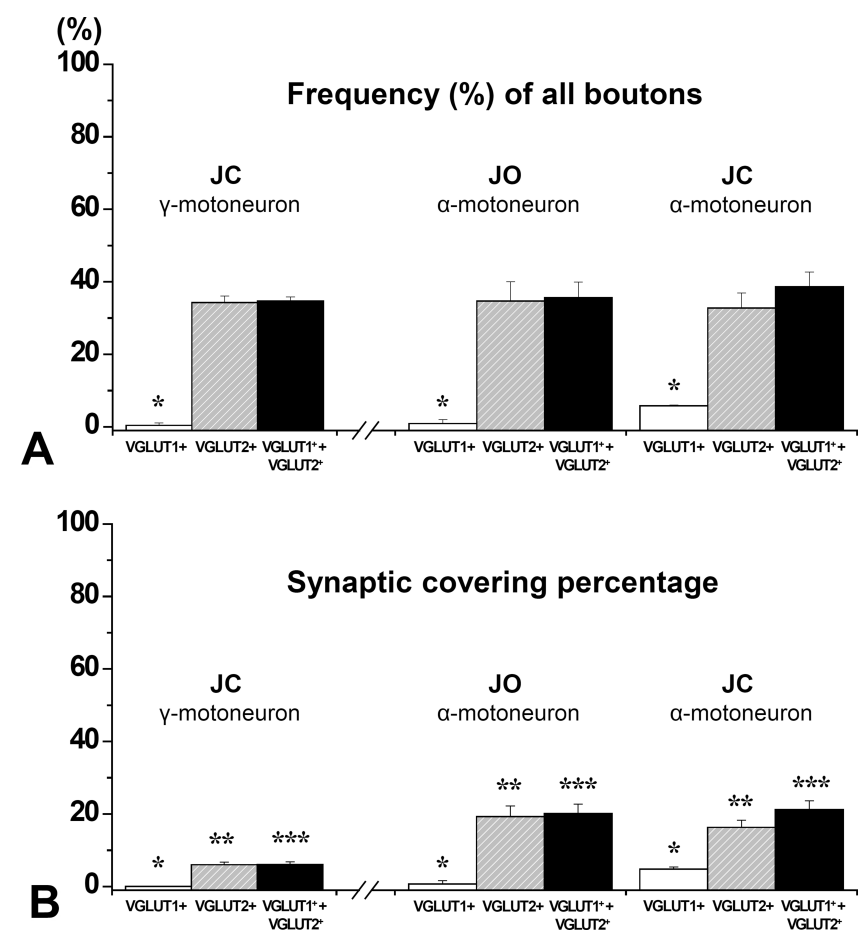

Fig. 3. Histograms showing the fraction (\%, mean \pm SD) of VGLUT+ boutons of all boutons (A) and their synaptic covering percentage (B) on the jaw-closing (JC) $\gamma$-motoneurons, jaw-opening (JO) and JC a-motoneurons. Single asterisk indicates significant difference between JC $\gamma$-/JO $\alpha$-motoneurons and JC $\alpha$-motoneurons (one-way ANOVA, $\mathrm{p}<0.05$ ) on VGLUT1+ boutons. Double and triple asterisks indicate significant difference between JC $\gamma$-motoneurons and JO/JC $\alpha$-motoneurons (one-way ANOVA, $\mathrm{p}<0.05$ ) on VGLUT2+ boutons and VGLUT1+ or VGLUT2+ boutons, respectively. Data on JC and JO $\alpha$-motoneurons are from our previously-published experiments and are provided for comparison [6]. and VGLUT2+ boutons on identified JC $\gamma$-motoneuron somata are summarized in Fig. 3 and Table 1. Analogous data on a-motoneurons collected from our previously-published experiments [6] are provided for comparison. About 35\% of the 249 boutons on identified JC $\gamma$-motoneurons were VGLUT-immunopositive, and of those, 99\% were VGLUT2-immunopositive. The fraction of VGLUT1+ boutons of all boutons contacting identified JC $\gamma$-motoneurons and the percentage of membrane covered by them were significantly smaller than those on the JC a-motoneurons (but the same as those on the JO a-motoneurons), whereas the synaptic covering percentage of the VGLUT2+ boutons on the JC $\gamma$-motoneurons was significantly lower than that of JO and JC a-motoneurons (Table 1).

The VGLUT2+ boutons on JC $\gamma$-motoneurons were uniformly small $\left(0.2 \sim 2.3 \mu \mathrm{m}^{3}\right)$, analogous to those on the JC $\alpha$-motoneurons $\left(0.7 \sim 7.9 \mu \mathrm{m}^{3}\right)$, and the JO $\alpha$-motoneurons $\left(0.5 \sim 3.9 \mu \mathrm{m}^{3}\right)$,

Table 1. Frequency ( $\%$, mean \pm SD) of VGLUT1+ and VGLUT2+ boutons and percentage of membrane covered by VGLUT1+ and VGLUT2+ boutons on the rat jaw-closing (JC) $\gamma$-motoneurons

\begin{tabular}{|c|c|c|c|}
\hline & $\begin{array}{c}\mathrm{JC} \gamma- \\
\text { moto- } \\
\text { neuron }\end{array}$ & $\begin{array}{l}\text { JOa- } \\
\text { moto- } \\
\text { neuron }\end{array}$ & $\begin{array}{c}\text { JCa- } \\
\text { moto- } \\
\text { neuron }\end{array}$ \\
\hline $\begin{array}{l}\text { No. of profiles examined } \\
\text { (from } 4 \text { rats) }\end{array}$ & 24 & 204 & 237 \\
\hline $\begin{array}{l}\text { Total membrane length } \\
\text { examined }(\mu \mathrm{m})\end{array}$ & 1084.6 & 3742.1 & 3934.2 \\
\hline No. of all boutons examined & 249 & 1883 & 1625 \\
\hline \multicolumn{4}{|l|}{ VGLUT1+ boutons } \\
\hline No. of boutons & 1 & 7 & 59 \\
\hline$\%$ of all boutons & $0.4 \pm 0.7^{\mathrm{a}}$ & $0.9 \pm 1.1^{\mathrm{a}}$ & $5.8 \pm 0.2^{\mathrm{a}}$ \\
\hline$\%$ of VGLUT1 + or & $1.1 \pm 2.2^{\mathrm{a}}$ & $2.9 \pm 3.6^{\mathrm{a}}$ & $15.2 \pm 1.4^{\mathrm{a}}$ \\
\hline $\begin{array}{l}\text { VGLUT2+ boutons } \\
\text { synaptic covering percentage }\end{array}$ & $0.02 \pm 0.04^{\mathrm{a}}$ & $0.7 \pm 0.9^{\mathrm{a}}$ & $4.8 \pm 0.6^{\mathrm{a}}$ \\
\hline \multicolumn{4}{|l|}{ VGLUT2+ boutons } \\
\hline No. of boutons & 85 & 333 & 342 \\
\hline$\%$ of all boutons & $34.3 \pm 1.8$ & $34.7 \pm 5.3$ & $32.8 \pm 4.1$ \\
\hline $\begin{array}{l}\% \text { of VGLUT1 + or } \\
\text { VGLUT2+ boutons }\end{array}$ & $98.9 \pm 2.2^{\mathrm{a}}$ & $97.1 \pm 3.6^{\mathrm{a}}$ & $84.8 \pm 1.4^{\mathrm{a}}$ \\
\hline synaptic covering percentage & $6.0 \pm 0.7^{\mathrm{b}}$ & $19.3 \pm 2.9^{\mathrm{b}}$ & $16.3 \pm 2.0^{\mathrm{b}}$ \\
\hline \multicolumn{4}{|l|}{$\begin{array}{l}\text { Total VGLUT1+ } \\
\text { or VGLUT2+ boutons }\end{array}$} \\
\hline $\begin{array}{l}\text { No. of VGLUT1+ or } \\
\text { VGLUT2+ boutons }\end{array}$ & 86 & 340 & 401 \\
\hline$\%$ of all boutons & $34.7 \pm 1.1$ & $35.6 \pm 4.3$ & $38.6 \pm 4.1$ \\
\hline synaptic covering percentage & $6.1 \pm 0.7^{\mathrm{b}}$ & $20.1 \pm 2.6^{\mathrm{b}}$ & $21.2 \pm 2.4^{\mathrm{b}}$ \\
\hline
\end{tabular}

"a" indicates significant difference between JC a-motoneurons and jawopening (JO) $a$-/JC $\gamma$-motoneurons (one-way ANOVA, Scheffe's post hoc test, $\mathrm{p}<0.05$ ).

"b" indicates significant difference between JC $\gamma$-motoneurons and JO/JC $a$-motoneurons (one-way ANOVA, Scheffés post hoc test, $\mathrm{p}<0.05$ ).

Data on JC and JO $a$-motoneurons are from our previously-published experiments and are provided for comparison [6]. 
and significantly smaller than the VGLUT1+ boutons on JC a-motoneurons $\left(3.3 \sim 29.8 \mu^{3}\right)$, the bouton features related to synaptic strength, including bouton volume, mitochondrial volume, and active zone area of the VGLUT2+ boutons on JC $\gamma$-motoneurons were significantly smaller than those of VGLUT1+ boutons on the JC $a$-motoneurons (but not different from those on the JO and JC a-motoneurons, Fig. 4).

The findings of the present study, 1) virtually all (99\%) VGLUT+ boutons on the JC $\gamma$-motoneurons are VGLUT2+, and 2) the bouton volume, mitochondrial volume and active zone area of the VGLUT2+ boutons on the JC $\gamma$-motoneurons are small and uniform, suggest that the JC $\gamma$-motoneurons receive uniformly-weak glutamatergic synaptic input almost exclusively from VGLUT2+ premotoneurons that form direct synapse with motoneurons.

Transection of the trigeminal motor root results in a loss of the VGLUT1+ puncta in the dorsolateral region of the Vmo, suggesting that the glutamatergic innervation of the JC motoneurons ultimately arises from the proprioceptive primary sensory neurons in the trigeminal mesencephalic nucleus (Vmes) that innervate muscle spindles [13]. Considering that $\gamma$-motoneurons do not receive direct proprioceptive input from muscle spindles [14], the VGLUT+ innervation of JC $\gamma$-motoneurons is likely to arise from intrinsic premotoneurons, not from Vmes neurons. That most of the VGLUT+ boutons on the JC $\gamma$-motoneurons were VGLUT2+ is analogous to the pattern of innervation of the JO a-motoneurons, but different from that of the JC a-motoneurons since a considerable fraction of the glutamatergic input to the latter arises from VGLUT1+Vmes neurons $[6,13,15]$. This lends morphological support to the notion that the glutamatergic innervation of JC $\gamma$-motoneurons arises mostly from VGLUT2+ intrinsic premotoneurons, and that VGLUT2-mediated glutamate release mechanism may play an essential role for the excitation of JC $\gamma$-motoneurons and for the isometric contraction of JC muscle during food chewing [16]. The fraction of VGLUT2+ boutons of all boutons was similar between the JC $\gamma$ - and $\alpha$-motoneurons. Whereas the fraction of VGLUT1+ boutons was far smaller on the JC $\gamma$-motoneurons than JC $a$-motoneurons receiving proprioceptive inputs. This is comparable with that the fraction of inhibitory boutons (GABA+ and/or glycine+ boutons) is smaller on the JC $\gamma$-motoneurons than JC a-motoneurons [4]. It suggests that JC $\gamma$-motoneurons are more weekly regulated and receive less inhibitory synapses than JC a-motoneurons that receive strong excitatory synapse from VGLUT1+ large boutons of the proprioceptive neurons. In the light of some evidence that VGLUT2+ neurons in the principal trigeminal, spinal trigeminal, and supra-trigeminal nuclei, and the pontomedullary reticular formation project to Vmo $[13,17]$, the VGLUT2 + boutons on the JC $\gamma$-motoneurons are assumed to arise from these brain regions.

In the brain regions including hippocampus and the cerebellum, VGLUT1 is found in synapses showing low release probability and high potential for synaptic plasticity and long-term potentiation; conversely, VGLUT2 is found in synapses with high release probability and low potential for synaptic plasticity and long-term depression $[1,18,19]$. If the same holds true for the trigeminal motor system, the virtually exclusively VGLUT2+ glutamatergic synapses on the JC $\gamma$-motoneurons may represent the lower propensity of this input for activity-dependent plasticity, perhaps reflecting the relatively poor adaptability of the evolutionally-old circuit dedicated to chewing of solid food.

The bouton volume, mitochondrial volume and active zone area of the VGLUT2+ boutons on the JC $\gamma$-motoneurons, all measures of synaptic strength, were uniformly small and similar to those of VGLUT1+ and VGLUT2+ boutons on the JO and JC $a$-motoneurons that originate from intrinsic premotoneurons [6], and different from those of VGLUT1+ boutons of the Vmes afferents [6] or primary sensory afferents, which are mostly large
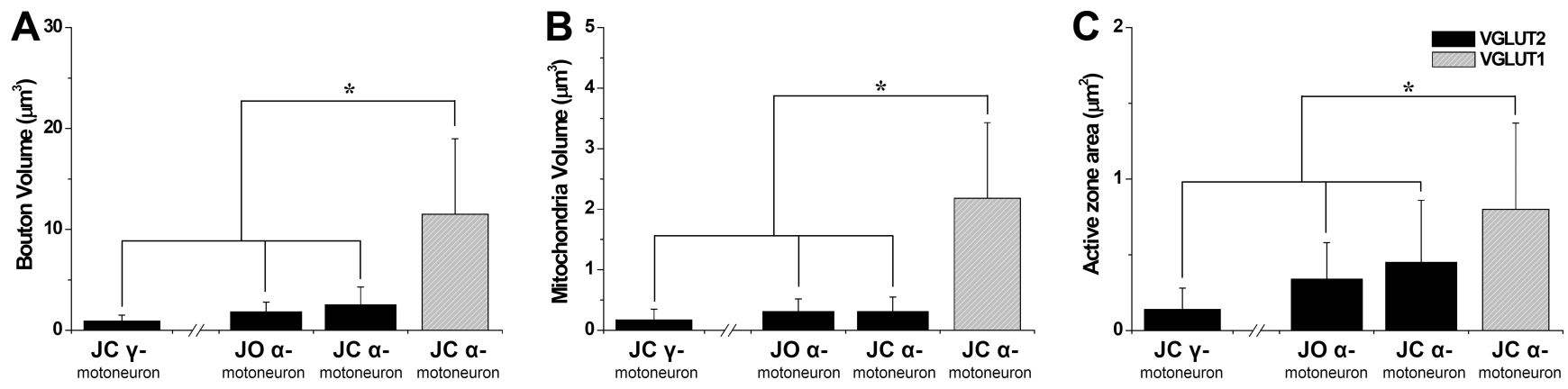

Fig. 4. Histograms showing bouton volume (A), mitochondrial volume (B), and active zone area (C) of the VGLUT1+ and VGLUT2+ boutons on the jaw-closing (JC) $\gamma$-motoneurons and $\alpha$-motoneurons and on the jaw-opening (JO) $\alpha$-motoneurons. All parameters are significantly smaller for VGLUT2+ boutons than for VLGUT1+ boutons. Data on JC and JO a-motoneurons are from our previously-published experiments and are provided for comparison [6]. 
$[6,20,21]$. We interpret this to suggest that the glutamatergic input originating from intrinsic premotoneurons exerts a much weaker influence on the JC $\gamma$-motoneurons (as well as on JC and $\mathrm{JO} \alpha$-motoneurons) than glutamatergic input originating from proprioceptive primary afferents, and it may be involved in the fine regulation of isometric contraction of the JC muscles. In the present study, quantitative analysis of the VGLUT+ boutons was performed on the somata of the JC $\gamma$-motoneurons. Considering that surface area of the dendrites occupy more than $93 \%$ of the total surface area of motoneurons [22,23], further study on the excitatory and inhibitory synapses in the dendrites of the JC $\gamma$-motoneurons is needed for thorough understanding of the regulation of the JC $\gamma$-motoneuron excitability.

\section{ACKNOWLEDGEMENTS}

The authors sincerely thank Dr. Juli Valtschanoff for helpful discussion and careful reading of the manuscript. This work was supported by the National Research Foundation of Korea (NRF) grant funded by the Korea government (MSIT, NRF2017R1A5A2015391, NRF-2017R1A2B2003561).

\section{REFERENCES}

1. Fremeau RT Jr, Voglmaier S, Seal RP, Edwards RH (2004) VGLUTs define subsets of excitatory neurons and suggest novel roles for glutamate. Trends Neurosci 27:98-103.

2. Liguz-Lecznar M, Skangiel-Kramska J (2007) Vesicular glutamate transporters (VGLUTs): the three musketeers of glutamatergic system. Acta Neurobiol Exp (Warsz) 67:207-218.

3. Ishihama K, Kogo M, Koizumi H, Nomura K, Tanaka S, Yamanishi T, Enomoto A (2003) Oral-motor patterns of rhythmic trigeminal activity generated in fetal rat brainstem in vitro. Brain Res Dev Brain Res 145:163-166.

4. Bae YC, Choi BJ, Lee MG, Lee HJ, Park KP, Zhang LF, Honma S, Fukami H, Yoshida A, Ottersen OP, Shigenaga Y (2002) Quantitative ultrastructural analysis of glycine- and gammaaminobutyric acid-immunoreactive terminals on trigeminal alpha- and gamma-motoneuron somata in the rat. J Comp Neurol 442:308-319.

5. Nishimura K, Ohta M, Saito M, Morita-Isogai Y, Sato H, Kuramoto E, Yin DX, Maeda Y, Kaneko T, Yamashiro T, Takada K, Oh SB, Toyoda H, Kang Y (2018) Electrophysiological and morphological properties of $a$ and $\gamma$ motoneurons in the rat trigeminal motor nucleus. Front Cell Neurosci 12:9.

6. Park SK, Ko SJ, Paik SK, Rah JC, Lee KJ, Bae YC (2018) Vesicular glutamate transporter 1 (VGLUT1)- and VGLUT2- immunopositive axon terminals on the rat jaw-closing and jaw-opening motoneurons. Brain Struct Funct 223:23232334.

7. Weinberg RJ, van Eyck SL (1991) A tetramethylbenzidine/ tungstate reaction for horseradish peroxidase histochemistry. J Histochem Cytochem 39:1143-1148.

8. Park SK, Kim JH, Yang ES, Ahn DK, Moon C, Bae YC (2014) Ultrastructure and synaptic connectivity of main and accessory olfactory bulb efferent projections terminating in the rat anterior piriform cortex and medial amygdala. Brain Struct Funct 219:1603-1613.

9. Mah W, Lee SM, Lee J, Bae JY, Ju JS, Lee CJ, Ahn DK, Bae YC (2017) A role for the purinergic receptor $\mathrm{P}_{2} \mathrm{X}_{3}$ in astrocytes in the mechanism of craniofacial neuropathic pain. Sci Rep 7:13627.

10. Bae JY, Lee JS, Ko SJ, Cho YS, Rah JC, Cho HJ, Park MJ, Bae YC (2018) Extrasynaptic homomeric glycine receptors in neurons of the rat trigeminal mesencephalic nucleus. Brain Struct Funct 223:2259-2268.

11. Paik SK, Yoo HI, Choi SK, Bae JY, Park SK, Bae YC (2019) Distribution of excitatory and inhibitory axon terminals on the rat hypoglossal motoneurons. Brain Struct Funct 224:17671779 .

12. Destombes J, Horcholle-Bossavit G, Thiesson D, Jami L (1992) Alpha and gamma motoneurons in the peroneal nuclei of the cat spinal cord: an ultrastructural study. J Comp Neurol 317:79-90.

13. Pang YW, Ge SN, Nakamura KC, Li JL, Xiong KH, Kaneko T, Mizuno N (2009) Axon terminals expressing vesicular glutamate transporter VGLUT1 or VGLUT2 within the trigeminal motor nucleus of the rat: origins and distribution patterns. J Comp Neurol 512:595-612.

14. Eccles JC, Eccles RM, Iggo A, Lundberg A (1960) Electrophysiological studies on gamma motoneurones. Acta Physiol Scand 50:32-40.

15. Pang YW, Li JL, Nakamura K, Wu S, Kaneko T, Mizuno N (2006) Expression of vesicular glutamate transporter $1 \mathrm{im}$ munoreactivity in peripheral and central endings of trigeminal mesencephalic nucleus neurons in the rat. J Comp Neurol 498:129-141.

16. Tsukiboshi T, Sato H, Tanaka Y, Saito M, Toyoda H, Morimoto T, Türker KS, Maeda Y, Kang Y (2012) Illusion caused by vibration of muscle spindles reveals an involvement of muscle spindle inputs in regulating isometric contraction of masseter muscles. J Neurophysiol 108:2524-2533.

17. Travers JB, Yoo JE, Chandran R, Herman K, Travers SP (2005) Neurotransmitter phenotypes of intermediate zone reticular 
formation projections to the motor trigeminal and hypoglossal nuclei in the rat. J Comp Neurol 488:28-47.

18. Dittman JS, Regehr WG (1998) Calcium dependence and recovery kinetics of presynaptic depression at the climbing fiber to Purkinje cell synapse. J Neurosci 18:6147-6162.

19. Fremeau RT Jr, Kam K, Qureshi T, Johnson J, Copenhagen DR, Storm-Mathisen J, Chaudhry FA, Nicoll RA, Edwards RH (2004) Vesicular glutamate transporters 1 and 2 target to functionally distinct synaptic release sites. Science 304:18151819.

20. Bae YC, Paik SK, Park KP, Ma SK, Jin JG, Ahn DK, Kim SK, Moritani M, Yoshida A (2004) Quantitative analysis of tooth pulp afferent terminals in the rat brain stem. Neuroreport 15:2485-2489.
21. Park SK, Lee DS, Bae JY, Bae YC (2016) Central connectivity of the chorda tympani afferent terminals in the rat rostral nucleus of the solitary tract. Brain Struct Funct 221:11251137.

22. Ulfhake B, Kellerth JO (1981) A quantitative light microscopic study of the dendrites of cat spinal alpha-motoneurons after intracellular staining with horseradish peroxidase. J Comp Neurol 202:571-583.

23. Fukunishi Y, Nagase Y, Yoshida A, Moritani M, Honma S, Hirose Y, Shigenaga Y (1999) Quantitative analysis of the dendritic architectures of cat hypoglossal motoneurons stained intracellularly with horseradish peroxidase. J Comp Neurol 405:345-358. 